\title{
Power market stability and risk management
}

\author{
Tan Weizhe ${ }^{1, \mathrm{a}} \mathrm{Yu}$ Xiaofeng ${ }^{2, \mathrm{~b}}$ Zhu Yeyang *3,c Jia Haibing ${ }^{4, \mathrm{~d}}$ He Xiangdong, \\ ${ }^{1}$ Huadian Shandong Energy Sales Co.,Ltd Jinan, China \\ ${ }^{2}$ China Huadian Corporation Ltd Shandong Company.Jinan, China \\ ${ }^{3}$ Huadian Electric Power Research Institute Co., Ltd Hangzhou, China \\ ${ }^{4}$ Huadian Shandong Energy Sales Co.,Ltd Jinan, China \\ ${ }^{5}$ China Huadian Corporation Ltd Shandong Company.Jinan, China
}

\begin{abstract}
At present, China is in the stage of transition from the monopoly and unified management mode of the traditional power system to an open power market. The formation of a good market model and rules can meet the needs of fair competition, improve the production efficiency and service level of power enterprises, and reduce production costs. This article mainly introduces three methods of stability analysis, and expounds the potential risks and solutions facing China's power market from the perspective of risk management.
\end{abstract}

\section{Introduction}

Nowadays, in the environment of the gradual formation of China's power market, security and stability issues have become progressively prominent after fundamental changes in power production, trading, and consumption [1]. Every member participating in the market hopes that their interests can be maximized. The relationship between technology and economy is extremely close, and the relationship that is more reliable than economical does not exist in the traditional sense [2]. At present, China is in the stage of transition from the monopoly and unified management mode of the traditional power system to the power market. Good market models and rules can meet the needs of fair competition, improve the production efficiency and service level of power companies, reduce production costs, and bring huge economic benefits. Unreasonable market design will hinder the operation and development of the power system, and improper handling may even lead to serious social consequences and economic losses. Therefore, it is particularly urgent to promote the healthy development of the electricity market through the study of electricity market stability. Therefore, it is necessary to establish a mathematical model that not only reflects the laws of physics, but also reflects the laws of mathematics, and combines technical economics with quantitative economics. The concept of risk is used to deal with the physical and economic stability of the power system.

\section{Stability analysis method}

\subsection{Deterministic method}

\footnotetext{
abndltwz@163.com,bfoxyxf@163.com

c*yeyangzh@usc.edu, ${ }^{\mathrm{d}} 729931360 @ 163 . c o m,{ }^{*}$ hxdstore@126.com
}

The deterministic method is the traditional stability analysis under the given system topology and parameters, operating conditions and disturbance mode. The reason why the deterministic method is easily accepted by engineering applications is that it is not computationally intensive and requires low raw data. Of course there are many disadvantages:

(1) Different operating conditions and the possibility of different accidents were not considered, and the oncein-a-century scenario was treated the same as the once-ina-month scenario.

(2) The economic losses caused by different power outages cannot be well distinguished, and the power supply reliability of important loads is equal to the general load.

(3) The cost-effectiveness of accident prevention and control measures cannot be evaluated.

With the opening of the power market and the increasing complexity of the power system, people will sooner or later realize that the deterministic analysis method cannot satisfy its profit maximization.

\subsection{Probabilistic method}

There are uncertainties in the parameters of the power system, and the operating conditions and disturbance scenarios are ever-changing, and it is impossible to fully reflect them with a limited number of typical situations. All put forward the concept of stability analysis, which determines the probability stability index of the power system according to the statistical characteristics of the main random factors that affect the stability of the system. To calculate system parameters, operating parameters and disturbance parameters cause a huge amount of calculations, which is extremely difficult to analyze. Therefore, probabilistic methods not only rely on the 
development and maturity of the theory, but also require long-term data accumulation.

Burchett started probabilistic analysis of power system static stability in 1977 [3]; the first article on probability analysis of transient stability was published by Billinton et al. in 1978 [4]. After that, the probabilistic analysis method has aroused widespread interest among electric power scholars all over the world, and other solutions have been proposed.

Probabilistic methods still cannot avoid all the shortcomings of deterministic methods.

\subsection{Risk method}

Both deterministic methods and probabilistic methods are purely technical viewpoints that do not consider economic losses and cannot provide quantitative support for the final decision.

Risk is the product of accident probability and accident consequence, reflecting the mathematical expectation of loss. Risk analysis method takes into account both technology and economy through its two elements. The currency-based analysis method effectively unifies the stability and the economy, and can directly and quantitatively compare the changes of different parameters, the influence of different disturbance scenarios and control measures on the security and stability of the system, thereby realizing economic and technological integration Analysis and decision-making. Therefore, the power market risk management based on risk method analysis is the only way to build the power market.

\section{Risk management}

\subsection{The concept of risk management}

There is currently no uniform definition of the term "risk". IEEE defines "risk" as the product of probability and consequence [5]. Its two elements are the probability of an accident and the impact of the accident. The concept of risk management was put forward by Huebner in 1930. It refers to the fact that each economic unit identifies, measures, and analyzes risks, and on this basis, effectively controls risks, and uses the most economical and reasonable method to comprehensively dispose of risks. A scientific management method that reduces various adverse consequences to a minimum [6].

\subsection{Significance of risk management}

Participants can maximize their profits through risk management. At the same time, it can also provide a guarantee for social and economic development, promote scientific and rational decision-making, and reduce the risk of decision-making. At this stage, gradually establishing a risk management system with risk management, risk identification, risk analysis, risk assessment and risk control is the inevitable development direction of the development of modern enterprise safety management, and it is also an objective requirement for the realization of safe transactions in the electricity market.

\subsection{Risks in the electricity market}

The reform of the electricity market has entered a new stage. Each pilot unit is formulating various medium- and long-term or spot market trading rules. Therefore, it is necessary to consider the risks that may arise in the operation of the electricity market. Risk management and control requires us to start with the existing risks. Only when risks are effectively controlled can the electricity market operate stably and for a long time and benefits can be guaranteed.

According to different classification basis, there are several classification methods of risk [10]:

(1) Divided by risk object: property risk, personal risk, liability risk and credit risk.

(2) Divided by reasons: natural risk, social risk, economic risk and technical risk.

(3) Divided according to risk tolerance: tolerable analysis and unbearable risk.

(4) Divided according to the nature of risk: static risk and dynamic risk.

The main risks in the electricity market today are as follows:

\subsubsection{Irregular management system and market mechanism defects:}

The domestic power market in China is still in the early stage of construction, lacks risk management systems and management systems, and does not have a comprehensive management framework. Decisions cannot be rationalized, scientifically analyzed and researched. The provinces are still exploring the market mechanism, and market members may In order to maximize the benefits, the defects of the market mechanism are used to make the market into trouble, which affects the accuracy of risk measurement to a certain extent. Once the risk error occurs, it will bring incalculable economic losses to the electricity market.

\subsubsection{Information security risk:}

Nowadays, transactions and settlements in the electricity market are all carried out based on the electricity trading platform. The data interfaces between the electricity trading platform and mobile applications and portals are increasing, and they have become the key targets of cyber attacks. The security situation of information systems is severe [8]. The scale of users using the platform has expanded rapidly, and the contradiction between the strong dependence of market development on the system, high requirements and the out-of-synchronization of information development has become increasingly prominent [9]. In terms of platform information security risks, the platform integrates a large amount of power grid security information and private information of market entities. If information security protection measures are not in place, and employees' information security 
awareness is weak, it is prone to risks of data loss, illegal tampering or information leakage. In terms of the risks of the safe and stable operation of the platform, due to the rapid increase in the number of market members using the platform, the untimely capacity increase and improper maintenance of the system, the operation speed of the platform slows down or even the operation is interrupted, affecting user transactions, and there is a risk of user investment and dismantling..

\subsubsection{Market members manage risk:}

With the continuous deepening of the reform of the power system, the number of people using the power system platform has shown an increasing trend. The increasing number of people will have more or less impact on the power market. It is possible that some members used false materials during registration, failed to submit the change materials in time for changes in the entity body, or negligent in the registration review of the trading institution, failed to understand the entry policy and changes in the entity body in time, and did not fully review after the change, which may lead to non-compliance Qualified market members participated in the transaction, and the result of the transaction was deemed noncompliant. The transfer mechanism for unfinished transactions of market members is not sound, and the transaction institution handles market member withdrawal procedures improperly, which may cause economic disputes in the transaction contract. At the same time, when trading institutions have insufficient market risk warnings and education for market members, and market members are not required to sign a transaction risk notice before registration, there is a legal risk that market members have not fully fulfilled their risk education obligations.

3.3.4 Abuse of market power: "Market power refers to the ability of certain members of the market to prevent new competitors from entering the market, or to increase the cost of competitors, and intentionally limit their own power generation output and services in order to form and maintain high market prices. These markets After members raise the market price, they will not increase their own costs or value." In a perfectly competitive market, every power generation company will bid at marginal costs to maximize its profits. However, in an imperfectly competitive market environment, due to the market monopoly power of power generation companies, the quotation curve of power generation companies with market power may completely deviate from the cost curve, and they can change the market price level through their market power monopoly. Make it deviate from the competitive price level and make a profit.

3.3.5 Market entity credit risk: At present, domestic and foreign experts have done a lot of research on the credit evaluation and risk of market entities [11-15]. Literature [16] builds a credit evaluation model for market entities and proposes ideas for credit system construction;
Literature [17] builds a credit evaluation system and management methods for large customers of power supply companies; Literature [18] establishes an early warning model for electricity fee recovery safety risks and electricity fee audits Safety early warning model; Literature [19] designed a credit risk early warning framework for power market entities, and constructed a credit risk evaluation index system.

Table1. Electricity credit rating

\begin{tabular}{|c|c|}
\hline \multirow{2}{*}{ Commercial credit } & $\begin{array}{c}\text { Proportion of regional capacity } \\
\text { Electricity consumption growth rate } \\
\text { Electricity contribution rate }\end{array}$ \\
\hline Safety credit & $\begin{array}{c}\text { Average number of bad accidents } \\
\text { Number of safety incidents } \\
\text { Degree of damage to power facilities }\end{array}$ \\
\hline $\begin{array}{c}\text { Behavioral Legal } \\
\text { Credit }\end{array}$ & $\begin{array}{c}\text { Average severity of illegal electricity use } \\
\text { Electricity theft } \\
\text { Notification of rectification times } \\
\text { Number of illegal electricity usage }\end{array}$ \\
\hline Economic legal credit & $\begin{array}{c}\text { Idea average electricity payment rate } \\
\text { Accumulated days in arrears } \\
\text { Cumulative arrears }\end{array}$ \\
\hline Cooperation credit & $\begin{array}{c}\text { Objective rate of repairs for business } \\
\text { customers }\end{array}$ \\
\hline
\end{tabular}

3.3.6 Financial risk: The introduction of the electricity market mechanism, on the one hand, has intensified the competition between the power generation side and the electricity sales side, and reduced a certain degree of monopoly, but the final result of the competition is reflected in the electricity price. As the most important part of the electricity market, electricity price is the electricity market reform. Core. In the environment of the electricity market, the main feature of electricity price that is different from other market price fluctuations is that it has strong volatility. For example, when the power supply is tight, the electricity price will rise sharply, so that each market participant can generate electricity. Enterprises down to users are faced with huge financial risks. If they are not effectively prevented and avoided, it will bring catastrophic consequences and even large-scale power outages. In addition, the contradiction between power supply and demand, system load rate, market power and other factors also increase the complexity of electricity prices.

\section{Risk response measures}

\subsection{Irregular management system and market mechanism defects}

Set up special personnel to manage system maintenance and make the system more standardized. Different levels of management personnel should be responsible for controlling different levels and types of security risks and gradually implementing security management, implementing the rules from the perspectives of rule approval, market access, management, punishment, and exit, and standardizing the process and system design in the process, To ensure that the connection is reasonable, the implementation is in place, and there are independent 
monitoring agencies to promptly report existing problems, strengthen the monitoring and analysis of market operations, and regularly submit market monitoring analysis reports to the National Energy Administration and its dispatched agencies in accordance with relevant regulations. The content of the market monitoring analysis report includes, but is not limited to: market quotations and operation conditions; market members' implementation of market trading rules; market structure indicators such as market shares of market entities; network congestion; abnormal quotations and other market abnormal events ; Market risk prevention and control measures and risk assessment; market trading rules revision suggestions, etc. If the above measures can be implemented, the spot market will achieve a stable and rapid start relatively smoothly.

\subsection{Information security risk}

Complete information system security protection rules and regulations, accountability mechanisms and technical defense systems in a timely manner, carry out loophole investigation and governance, and eliminate platform security risks. Pre-judge the development of the electricity market, plan ahead for the software and hardware construction of the platform, and improve the trading platform's ability to deal with cloud data. Establish a platform dual-active standby system, formulate disaster preparedness emergency recovery plans, strengthen disaster preparedness emergency drills, and improve the level of platform safety and stability.

\subsection{Market members manage risk}

Strengthen the review of registration and withdrawal of market members, and strictly implement procedures. In accordance with government department access regulations, pay attention to the impact of relevant changes on the trading qualifications of market members. Strengthen the management of registered members, remind the registered market members to change the information in time if the information changes, and promptly clear the unqualified market members. Strengthen the appropriate management of market members, fulfill the risk education obligations of trading institutions, and prevent legal risks of trading institutions. [7]

\subsection{Abuse of market power}

By conducting fair market competition in the market, or through administrative measures such as market supervision, restraining market power, avoiding the conditions for forming market power as much as possible when designing the market, increasing the flexibility of electricity demand, increasing the proportion of long-term contracts, and adopting power generation quotations Curve bidding methods and other methods can effectively suppress the adverse effects of market power on the electricity market, and predict market power through models in advance, predict possible abuses of market power, and carry out market supervision in a timely manner.

\subsection{Financial risk}

The risk of electricity price can be avoided by developing the electricity futures market, because the futures market has a price discovery function and a hedging function. The price discovery function enables the power supply and demand relationship, future market conditions, power production costs and other physical attributes influencing factors to be reflected in the futures market, Which increases the transparency of the market, thereby slowing down the fluctuation of electricity prices and promoting the stable operation of the electricity market. On the other hand, the hedging function of the futures market can realize risk transfer and transfer the risk of future market price fluctuations to speculators in the futures market. , And the investment behavior of speculators will not affect the stable operation of the electricity market, and can help market participants avoid risks, reduce losses, and promote the safe development of the electricity market.

On the other hand, the establishment of a power generation reserve capacity market can avoid uncontrollable physical risks on the grid side such as generator set failure, transmission grid blockage, and excessive load. Too much reserve capacity will increase a lot of costs and reduce the economics of the power system. The reserve capacity will increase the risk tolerance of the power system. Therefore, a power reserve market can be established to ensure that generators who provide backup can also obtain corresponding profits, and generators without reserve capacity can also avoid certain financial risks.

\section{Conclusion}

Nowadays, the continuous reform of China's power system has also caused the power market to encounter challenges and risks that have never been encountered before. Therefore, it is necessary for relevant departments to strengthen their management and control and improve their ability to prevent risks in their daily work, and to be more standardized and scientific in their operations. Power generation companies need to improve risk management awareness and improve the system on the existing basis.

\section{References}

1. Xue Yusheng. The blackout defense framework based on space-time coordination (1) From isolated defense line to comprehensive defense[J]. Automation of Electric Power Systems, 2006, (1).

2. Xue Yusheng. The blackout defense framework of coordination of time and space (3) The optimization of each line of defense and the coordination between different lines of defense[J]. Automation of Electric Power Systems, 2006, (3).

3. Guo Chen, Wang Xifan, Zhang Xian.The investment risk decision of thermal power plant based on utility 
function[J].Automation of Electric Power Systems,2006

4. Xue Yusheng. A blackout defense framework based on space-time coordination (2) Wide-area information, online quantitative analysis and adaptive optimization control[J].Automation of Electric Power Systems,2006,(2).

5. Chi Zhenggang, Zhang Min.The influence of the forward contract market on the stability of the electricity market[J].Automation of Electric Power Systems, 2005

6. Han Zhenxiang, Gan Deqiang.A series of reports on the 2004 International Large Power Grid Conference-Study on hot issues in the electricity market[J].Automation of Electric Power Systems,2005,(2).

7. Yang Zhihui, Liu Youfei, Tang Yun, et al. Analysis on the Stability of Electricity Market[J].Proceedings of the Chinese Society for Electrical Engineering,2005,

8. Liu Youfei, Wu Fuli.Impact of Line Transmission Capacity Constraint on Electricity Market Equilibrium[J].Automation of Electric Power Systems, 2005

9. Zhang Xiaodong, Guan Lei, Zeng Ming, et al. Analysis of SFE Model of Electricity and Reserve Common Market[J].Automation of Electric Power Systems, 2005

10. Li Liying, Zhang Ximing, Peng Jianchun, et al. Demand-side power purchase strategy based on congestion risk[J].Power Automation Equipment,2005,(8)

11. Zheng Aimin, Xiong Jian and Zhang Fan. Order Financing Risk Pre-warning Model Based on BP Network. Journal of Intelligence. 2010.29(11):23-29.

12. Han Lu. Wang, Jing. Lu, Chunyan and Xie, Junqi. (2010) Research on early warning system of water quality safety based on RBF neural network model[M].Information Science and Engineering (ICISE), 2nd International Conference on .2010.2:4667-4670.

13. A risk measurement tool for an underground electricity distribution system considering the consequences and uncertainties of manhole events[J]. Reliability engineering \& system safety,2014:68-80.

14. Borensein, Severin. Customer risk from real-time retail electricity pricing: Bill volatility and hedgability[J]. Energy Journal, 2007, 28(2): 111-130.

15. Wang Yuping, Liu Lei, Zhu Ming, Zhu Gangyi, Gao Fangping, Li Mingli, Xiao Jian. Research and practice on credit management of power market-oriented transaction entities [J]. Electric Power Big Data, 2019, 22(05): 1-5.

16. Wang Yuzhe, Lei Xia, Chen Xiaosheng, et al. Research on the Credit Rating Evaluation of Power Major Clients Based on BP Neural Network[J]. Power Demand Side Management,2015,17(05) :49-53..
17. Gao Fangping, Li Mingli. Research on the Credit Risk Prevention Mechanism of Electricity Market Users Based on Data Mining of Payment Behavior[C]// The 2018 Academic Annual Meeting of the Electricity Market Professional Committee of the Chinese Society for Electrical Engineering and the National Electricity Trading Institution Alliance Forum. 0..

18. Research on Credit Evaluation and Electricity Charge Risk Management of Power Supply Company's Major Customers[D]. Chen Yanchao. North China Electric Power University 2015.

19. Yang Ting, Liu Dunnan, Liu Jiangyan, Shen Yue, Huang Yupeng, Chen Chunyi. Credit risk early warning model for power market entities[C].. Proceedings of the 2019 Academic Annual Meeting of the Power Market Professional Committee of the Chinese Society for Electrical Engineering and the Forum of the National Power Trading Institution Alliance Forum. China Electrical Engineering Society Electric Power Market Professional Committee, 2019: 176-182. 